\title{
PENGARUH HARGA TERHADAP VOLUME PENJUALAN MIE INSTAN GORENG PADA MINIMARKET INDOMARET MANISREJO DI KOTA MADIUN
}

\author{
Adrianus Widya Kristianto \\ Mahasiswa Prodi Pendidikan Ekonomi IKIP PGRI Madiun
}

\begin{abstract}
In general, the high and low price of a commodity is very important for a trading company in selling the products so increasing its sales volume. Price is one element of a marketing strategy is used as a benchmark for consumers to obtain goods or services, so as to achieve the objectives of the company (at a profit). While sales volume is all of the sales result that can be achieved by a company and can be measured by specific units. Usually the lower price of product it can increase sales volume, while high price of product will resulting in decreased sales volume. But in fact the consumers is often assume the price is the determining factor of a product quality, high price goods is generally considered to have better quality than the goods whose have low prices. The method used in the research is quantitative, the research conducted at Minimarket especially in Indomaret Manisrejo Madiun city. The data obtained from the documentation of the closing monthly data of Indomaret Manisrejo in Madiun which are contain list price and sales volume. The result of analysis data obtained in this research using regression correlation test, $F$ test, and $t$ test. In correlation values obtained $r_{\text {hit }} \leq r_{\text {tabel }}(0,396 \leq 0,444)$ or $\operatorname{sig}_{\text {hit }} \geq \operatorname{sig}_{\text {prob }}(0,84 \geq 0,05)$, so we can conclude that $\mathrm{H}_{0}$ is accepted it means there is no relationship between the price of the fried instant noodle sales volume in minimarket Indomaret Manisrejo in Madiun city. Fisher's test values obtained in $\mathrm{F}_{\text {hit }} \leq \mathrm{F}_{\text {tabel }}(3,339 \leq$ $4,414)$ or $\operatorname{sig}_{\text {hit }} \geq \operatorname{sig}_{\text {prob }}(0,84 \geq 0,05)$. So we can conclude that $H_{0}$ is accepted its means that no price impact on the sales volume of instant fried noodle on minimarket Indomaret Manisrejo in Madiun. While in regression coefficient test / test $\mathrm{t}$ values obtained $\mathrm{t}_{\text {hit }} \leq \mathrm{t}_{\text {tabel }}$ $(-1,827 \leq 0,842)$ or values $\operatorname{sig}_{\text {hit }} \geq \operatorname{sig}_{\text {prob }}(0,84 \geq 0,05)$, it can be concluded that $H_{0}$ is accepted, it means that there is no difference price to price effect of sales volume fried instant noodle on minimarket Indomaret Manisrejo in Madiun.
\end{abstract}

Keywords: price, sales volume

\section{PENDAHULUAN}

Mengingat semakin pesatnya pertumbuhan barang dan jasa yang dibutuhkan oleh konsumen, baik dalam jumlah maupun jenisnya, maka hal ini mendorong perusahaan-perusahaan dagang untuk saling berpacu agar dapat memuaskan kebutuhan konsumen dengan cara menjual barang dan jasa dengan harga terjangkau sesuai dengan keinginan konsumen agar dapat meningkatkan volume penjualannya. Dengan perkembangan dan persaingan yang semakin ketat akan membawa hasil usaha pada situasi yang tidak menentu, sehingga banyak usaha yang akhirnya bangkrut atau gulung tikar karena tidak mampu memperta- 
hankan usahanya. Dalam kondisi yang demikian maka harus dipikirkan suatu cara untuk tetap mempertahankan usahanya agar tetap bertahan dan lebih berkembang lagi, sehingga suatu perusahaan dituntut untuk dapat melakukan suatu usaha agar dapat menghadapi persaingan yang begitu pesat. Guna menghadapi persaingan yang begitu ketat tersebut, maka perlu dilakukaan strategi-strategi pemasaran yang tepat untuk dapat meningkatkan volume penjualan, salah satunya yaitu dengan cara penetapan harga.

Pertumbuhan ritel di Indonesia tercermin dengan pesatnya pertumbuhan minimarket sebagai salah satu pasar modern dan ritel di Indonesia. Diantaranya yaitu dengan munculnya Indomaret dan Alfamart diberbagai pelosok daerah atau pemukiman padat penduduk. Indomaret adalah minimarket atau perusahaan dagang ritel yang menerapakan sistem swalayan, dimana pembeli mengambil sendiri barang yang dibutuhkan dari rak-rak dagangan dan membayar dikasir. Sasaran pasar Indomaret adalah konsumen semua kalangan masyarakat. Lokasi toko yang strategis dimaksudkan untuk memudahkan Indomaret dalam melayani kebutuhan keluarga sehari-hari.

Pada umumnya setiap perusahaan dalam menjalankan kegiatannya mempunyai tujuan akhir, yaitu untuk menjual barang/jasa tersebut kepada masyarakat. Sama halnya dengan perusahaan yang bergerak di bidang penjualan produk eceran atau ritel seperti Indomaret ini selalu berfokus pada masalah barang yang hendak dijual agar dapat laku di pasaran, dan bagaimana harga barang yang dijual tersebut sesuai dengan selera serta terjangkau bagi konsumen. Basu Swastha (2002:183) berpendapat bahwa "Penjulan ini merupakan fungsi yang paling penting dalam pemasaran karena menjadi tulang punggung kegiatan untuk mencapai pasar yang dituju. Fungsi penjualan juga merupakan sumber pendapatan yang diperlukan untuk menutup ongkos-ongkos dengan harapan bisa mendapatkan laba”. Penjualan memegang peranan penting bagi perusahaan agar dapat menjual berbagai macam produk dan dapat meningkatkan volume penjualan sehingga memberikan hasil maksimal bagi perusahan. Dengan kata lain, apakah usaha itu dapat berhasil atau tidak, sangat tergantung kepada keberhasilan penjualan itu sehingga keberhasilan usaha penjualan dapat dilihat dari volume penjualan yang didapat.

Freddy Rangkuti (2009:57) berpendapat bahwa "Volume penjualan adalah pencapaian penjualan yang dinyatakan secara kuantitatif dari segi fisik atau volume atau unit suatu produk". Semakin besar jumlah penjualan yang dihasilkan oleh perusahaan, maka semakin besar kemungkinan laba yang dihasilkan oleh perusahaan tersebut sehingga volume penjualan merupakan salah satu hal penting yang harus dievaluasi agar tidak rugi. Jadi, volume penjualan yang menguntungkan harus menjadi tujuan utama perusahaan. Dengan demikian, fokus kegiatan perusahaan adalah usaha meningkatkan cara-cara penjualan dan penetapan harga yang intensif agar dapat meningkatkan volume penjualan demi kelangsungan hidup perusahaan untuk tumbuh dan berkembang. Penetapan harga yang tepat diharapkan dapat meningkatkan volume penjualan dan tetap dapat menjaga kelangsungan usahanya.

Guna memenuhi selera konsumen yang beraneka ragam tersebut, maka salah satu strategi yang di lakukan Minimarket Indomaret Manisrejo di kota Madiun diantaranya dalam strategi produk, misalnya dengan menyediakan produk-produk yang digemari oleh konsumen dan sesuai dengan selera konsumen tersebut. Lebih dari 4.500 jenis produk makanan dan non makanan tersedia di Indomaret Manisrejo Madiun dengan harga bervariasi dan memenuhi hampir semua kebutuhan konsumen sehari-hari.

Salah satu produk makanan yang paling laku dan digemari oleh masyarakat adalah mie instan. Sekitar 16 merk mie instan dengan 92 macam jenis, rasa dan harga yang bervariasi tersedia di Indomaret Manisrejo Madiun dan tersusun rapi di rak-rak toko dengan display yang menarik. Hal ini dimaksudkan agar memudahkan konsumen dalam memilih merk, rasa, dan harga mie instan yang bervariasi.

"Pada umumnya tingkat harga yang le- 
bih rendah akan mengakibatkan jumlah yang diminta lebih besar” (Basu Swastha, 2008: 243). Atau dengan kata lain, tingkat harga yang lebih rendah tersebut pada umumnya akan berpengaruh terhadap peningkatan volume penjualan, sebaliknya apabila harga tinggi maka volume penjualan akan menurun. Sebab, konsumen akan mengurangi kuantitas yang dibeli jika harga suatu barang naik dan pada tingkat harga tinggi maka konsumen cenderung untuk berpindah ke produk pengganti yang harganya lebih rendah. Oleh karena itu tujuan penelitian ini adalah untuk mengetahui bagaimana Pengaruh Harga Terhadap Volume Penjualan Mie Instan goreng Pada Minimarket Indomaret Manisrejo Di Kota Madiun.

\section{METODE PENELITIAN}

Tempat penelitian dilaksanakan di Minimarket Indomaret Manisrejo di kota Madiun. Penelitian ini termasuk dalam kelompok penelitian kuantitatif karena data yang digunakan dalam bentuk angka. Hal ini di pertegas oleh pendapat J. Supranto (2008: 8) yang menyatakan bahwa "Data kuantitatif adalah data yang dinyatakan dalam bentuk angka”.

Secara sitematis rancangan penelitian dapat dilihat pada gambar sebagai berikut.

\begin{tabular}{|c|c|}
\hline HARGA & VOLUME PENJUALAN \\
\hline
\end{tabular}

Dalam penelitian ini yang menjadi variabel bebas (X) adalah harga dan variabel terikat (Y) adalah volume penjualan. Yang menjadi populasi pada penelitian ini satuan atau objek yang diteliti adalah bulan sejak berdirinya Indomaret Manisrejo madiun pada bulan April tahun 2003 sampai bulan Desember 2012. Sedangkan sampel yang digunakan dalam penelitian ini yaitu 24 bulan. Teknik pengumpulan data yang digunakan dalam penelitian ini adalah teknik dokumentasi, yaitu berupa data tutup bulanan / clossing di Indomaret Manisrejo Madiun pada bulan Januari 2011 sampai dengan bulan Desember 2012. Karena selama bulan Januari 2011 sampai dengan bulan Desember 2012 tersebut harga mie instan goreng pada Indomaret Manisrejo Madiun tidak mengalami perubahan.

Peneliti melakukan penggalian informasi melalui dokumentasi dengan meminta data tutup bulanan pada Indomaret Manisrejo di kota Madiun selama 24 bulan. Proses tutup bulanan ini dilakukan setiap akhir bulan sekali. Data tutup bulanan ini terdapat daftar harga produk dan volume penjualan yang di peroleh dalam kurun waktu 1 bulan.

Sehubungan dengan penelitian ini, peneliti menemukan 2 variabel yang akan di teliti. Burhan Bungin (2009: 59) berpendapat bahwa “ ... variabel adalah sebuah fenomena (yang berubah-ubah) dengan demikian maka bisa jadi tidak ada satu peristiwa di alam ini yang tidak dapat disebut variabel, tinggal tergantung bagaimana kualitas variabelnya, yaitu bagaimana bentuk variasi fenomena tersebut”. Hal ini di perjelas oleh Suharsimi Arikunto (2002: 96) yang berpendapat bahwa "Sekali lagi, variabel adalah objek penelitian, atau apa yang menjadi titik perhatian suatu penelitian”.

\section{Teknik Pengumpulan Data}

Teknik pengumpulan data dalam penelitian ini menggunakan teknik dikumentasi untuk memperoleh keterangan maupun informasi yang dapat digunakan sebagai bahan untuk penelitian, untuk mendapatkan data yang diperlukan maka peneliti menggunakan teknik pengumpulan data dengan metode dokumentasi.

"Metode dokumentasi ini pada umumnya didapat dari data-data perusahaan. Data perusahaan merupakan data-data internal suatu perusahaan, misalnya: jurnal-jurnal, laporan penjualan, surat-surat, faktur, dll” (Gabriel Amin, 2003: 82).

“... metode dokumentasi yaitu mencari data mengenai hal-hal atau variabel yang berupa catatan, transkrip, buku, surat kabar, majalah, prasasti, notulen, rapat, lengger, agenda, dan sebagainya” (Suharsimi Arikunto, 2002: 206). 
Hal ini diperjelas oleh Burhan Bungin (2005: 144) yang berpendapat bahwa "Metode dokumenter adalah suatu metode pengumpulan data yang digunakan dalam metodologi penelitian sosial. Pada intinya metode dokumenter adalah metode yang digunakan untuk menelusuri data historis".

Dokumentasi yang diperlukan oleh peneliti berupa data tutup bulanan/clossing pada minimarket Indomaret Manisrejo pada bulan Januari 2011 sampai dengan bulan Desember 2012 yang didalamnya terdapat daftar harga produk mie instan goreng dan volume penjualan yang didapatkan pada setiap bulannya. Dikhususkan hanya mengambil data berupa daftar harga dan volume penjualan mie instan goreng sebagai subyek penelitian, karena Gabriel Amin $(2003,61)$ berpendapat bahwa "Penelitian sampel atau metode sampling boleh dilakukan apabila keadaan subyek di dalam populasi benar-benar homogen”.

Untuk mendapatkan data tutup bulanan / clossing ini, peneliti harus menemui Kepala Toko Indomaret Manisrejo Madiun selaku pimpinan di minimarket tersebut dengan membawa surat permohonan penelitian dari lembaga. Setelah itu kepala toko meminta persetujuan dari supervisor selaku pimpinan area cabang Madiun karena untuk dapat mencetak data tersebut diperlukan password yang hanya di ketahui oleh supervisornya saja sehingga dapat terjamin kerahasiaanya agar data-data tersebut tidak sampai jatuh ke tangan kompetitor.

\section{Instrumen Penelitian}

"Instrumen penelitian adalah alat atau fasilitas yang digunakan oleh peneliti dalam mengumpulkan data agar pekerjaannya lebih mudah dan hasilnya lebih baik, dalam arti lebih cermat, lengkap, dan sistematis sehingga lebih mudah diolah" (Suharsimi Arikunto, 2002: 136).

Suharsimi Arikunto (2005: 167) menyatakan bahwa "Sebuah instrumen dikatakan memiliki validitas logis apabila instrumen tersebut secara analisis akal sudah sesuai dengan isi dan aspek yang diungkapkan. Instrumen yang sudah sesuai dengan isi dikatakan sudah memiliki validitas isi sedangkan instrumen yang sudah sesuai dengan aspek yang diukur dikatakan sudah memiliki validitas konstruksi”.

Sehubungan dengan hal tersebut, data yang diperlukan dalam penelitian ini digunakan dokumentasi berupa data tutup bulanan/ clossing di minimaret Indomarket Manisrejo Madiun pada bulan Januari 2011 sampai dengan bulan Desember 2012 yang didalamnya terdapat daftar harga produk mie instan goreng dan volume penjualan yang didapatkan pada setiap bulannya.

\section{Teknik Analisis Data}

"Menganalisis data merupakan suatu langkah yang sngat kritis dalam penelitian. Peneliti harus memastikan pola analisis mana yang harus digunakannya, apakah analisis statistik ataukah analisis non-statistik" (Sumadi Suryabrata, 2012: 40).

Hal ini diperjelas oleh Gabriel Amin (2003: 88) berpendapat bahwa “Analisa ini merupakan tahap yang penting dan menentukan. Pada tahap ini data dikerjakan dan dimanfaatkan sedemikian rupa sampai berhasil menyimpulkan kebenaran-kebenaran yang dapat dipakai untuk menjawab persoalan-persoalan yang diajukan dalam penelitian”.

Sebagai tindak lanjut dari hasil pengumpulan data, maka data tersebut perlu diolah dan dianalisis sehingga diperoleh kesimpulan yang sesuai dengan tujuan diadakannya penelitian. Analisa data dalam penelitian ini yaitu menghitung nilai mengenai harga terhadap volume penjualan mie instan goreng pada minimarket Indomaret Manisrejo di kota Madiun berdasarkan data hasil dokumentasi, kemudian data tersebut diolah untuk mendapatkan nilai persentase. Untuk melakukan analisa dan penghitungan di atas, maka digunakan bantuan komputer dengan memanfaatkan paket Program SPSS (Statistical Program for Social Science) for Windows 16.0. 


\section{HASIL PENELITIAN}

\section{Variabel Harga}

Deskripsi variabel harga (x) dalam penelitian ini yaitu harga produk mie instan goreng pada minimarket Indomaret Manisrejo Madiun yang telah diteliti.

Dari data dokumentasi yang terdiri dari 20 item mie instan goreng dengan harga yang bervariasi dan dinyatakan dalam satuan $\mathrm{Ru}-$ piah.

Dari penelitian diperoleh data bahwa produk yang paling banyak diminati oleh konsumen adalah Indomie goreng special dengan harga Rp. 1.550,- dan berikutnya adalah mie Sedaap goreng, Sarimi goreng, Supermi goreng, dan lain-lainnya yang harganya jauh lebih murah dibandingkan dengan Indomie goreng special. Sedangkan produk mie instan goreng yang harganya Rp. 2000,- jarang diminati oleh konsumen.

\section{Variabel Volume Penjualan}

Volume penjualan mie instan goreng pada minimarket Indomaret Manisrejo Madiun ini diperoleh dari dokumentasi berupa data tutup bulanan / Clossing pada minimarket Indomaret Manisrejo Madiun selama 24 bulan (Januari 2011 sampai dengan Desember 2012) yang dinyatakan dalan satuan unit barang yang terjual.

Dari penelitian dapat dilihat bahwa volume penjulan terbanyak adalah Indomie goreng special dan berikutnya adalah mie Sedaap goreng, Indomie goreng vegan, Sarimi goreng, Supermi goreng, dan lain-lainnya.

\section{Hasil Uji Korelasi}

Hasil uji korelasi didapat nilai $\mathrm{r}_{\text {hit }}$ sebesar 0,396 sedangkan $r_{\text {tabel }}$ sebesar 0,444. Hal ini berarti $r_{\text {hit }} \leq r_{\text {tabel }}(0,396 \leq 0,444)$. Di sisi lain sig $_{\text {hit }}$ sebesar 0,84 sedangkan sig prob $_{\text {adalah } 0,05}$. Hal ini berarti $\operatorname{sig}_{\text {hit }} \geq \operatorname{sig}_{\text {prob }}(0,84 \geq 0,05)$ Maka $\mathrm{H}_{0}$ diterima, hal ini dapat diartikan bahwa tidak ada hubungan antara harga dengan volume penjualan mie instan goreng pada minimarket Indomaret Manisrejo di kota
Madiun. Di lain pihak dalam uji determinasi yang diperoleh $\mathrm{R}^{2}$ atau $\mathrm{R}$ Square (koefisien determinasi) yang digunakan untuk mengetahui seberapa besar prosentase sumbangan harga terhadap volume penjualan nilai $\mathrm{R}^{2}$ adalah 15,60\%. Jadi sumbangan dari pengaruh harga terhadap volume penjualan mie instan goreng pada minimarket Indomaret Manisrejo Madiun adalah 15,60\% sedangkan sisanya sebesar 84,40\% dipengaruhi oleh faktor lain yang tidak diteliti, misalnya saja faktor selera konsumen, merek, rasa maupun loyalitas konsumen.

\section{Uji Fisher}

Dari hasil uji fisher diperoleh nilai $\mathrm{F}_{\text {hit }}$ sebesar 3,339 sedangkan $\mathrm{F}_{\text {tabel }}$ sebesar 4,414. Hal ini berarti $F_{\text {hit }} \leq F_{\text {tabel }}(3,339$ d” 4,414). Di sisi lain sig $_{\text {hit }}$ sebesar 0,84 sedangkan sig prob adalah 0,05 . Hal ini berarti $\operatorname{sig}_{\text {hit }} \geq \operatorname{sig}_{\text {prob }}(0,84$ $\geq 0,05)$. Maka $\mathrm{H}_{0}$ diterima, hal ini dapat diartikan bahwa tidak ada pengaruh harga dengan volume penjualan mie instan goreng pada minimarket Indomaret Manisrejo di kota Madiun.

Selain digunakan untuk mencari pengaruh, uji Fisher atau Anova ini juga digunakan untuk uji linearitas. Karena $\mathrm{F}_{\text {hit }}(3,339) \leq \mathrm{F}_{\text {tabel }}$ $(4,414)$, maka dapat diartikan bahwa tidak ada hubungan yang linear antara variabel harga dengan volume penjualan.

\section{Uji t}

Atas dasar tabel uji t dapat dibuat persamaan regresi diperoleh persamaan nilai $\mathrm{Y}=7709,415-1,789 \mathrm{X}$ maka dapat diartikan bahwa jika harga meningkat $1 \%$ maka volume penjualan akan mengalami penurunan 1,789\% sedangkan faktor lainnya tetap. Hasil perhitungan diperoleh nilai $\mathrm{t}_{\text {hit }}$ sebesar $-1,827$ sedangkan $\mathrm{t}_{\text {tabel }}$ sebesar 0,842 . Hal ini berarti $t_{\text {hit }} \leq t_{\text {tabel }}(-1,827 \leq 0,842)$. Di sisi lain sig

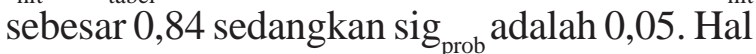
ini berarti $\operatorname{sig}_{\text {hit }} \geq \operatorname{sig}_{\text {prob }}(0,84 \geq 0,05)$. Atas dasar uji t tersebut dapat disimpulkan $\mathrm{H}_{0}$ diterima, artinya tidak ada beda pengaruh harga dengan volume penjualan mie instan goreng 
Coefficients

\begin{tabular}{|c|c|c|c|c|c|}
\hline \multirow[b]{2}{*}{ Model } & \multicolumn{2}{|c|}{ Unstandardised Coefficients } & \multirow{2}{*}{\begin{tabular}{|c} 
Standardised Coefficients \\
Beta \\
\end{tabular}} & & \multirow[b]{2}{*}{ Sig. } \\
\hline & B & Std. Error & & & \\
\hline 1 (Constant) & 7709.415 & 2681.474 & & 2.875 & .01 \\
\hline harga & -1.789 & 0.979 & -.396 & -1.827 & .084 \\
\hline
\end{tabular}

a. Dependent Variable: volume_penjualan

pada minimarket Indomaret Manisrejo di kota Madiun.

\section{SIMPULAN HASIL ANALISIS}

Atas dasar hasil pengujian hipotesis dapat diambil simpulan sebagai berikut.

\section{Simpulan Uji Korelasi}

Hasil dari pengujian korelasi diperoleh nilai $r_{\text {hit }}$ sebesar 0,396 sedangkan $r_{\text {tabel }}$ sebesar 0,444 . Hal ini berarti bahwa $r_{\text {hit }} \leq r_{\text {tabel }}(0,396 \leq$ $0,444)$ atau $\operatorname{sig}_{\text {hit }} \geq \operatorname{sig}_{\text {prob }}(0,84 \geq 0,05)$. Selain itu diperoleh nilai $\mathrm{R}^{2}$ adalah $15,60 \%$. Jadi sumbangan dari pengaruh harga terhadap volume penjualan mie instan goreng pada minimarket Indomaret Manisrejo Madiun adalah 15,60\%

Sesuai hipotesis yang diajukan dapat disimpulkan bahwa $\mathrm{H}_{0}$ diterima, artinya tidak ada hubungan antara harga terhadap volume penjualan mie instan goreng pada minimarket Indomaret Manisrejo di kota Madiun.

\section{Simpulan Uji Fisher}

Hasil dari pengujian Fisher diperoleh nilai $\mathrm{F}_{\text {hit }}$ sebesar 3,339 sedangkan $\mathrm{F}_{\text {tabel }}$ sebesar 4,414. Hal ini berarti $\mathrm{F}_{\text {hit }} \leq \mathrm{F}_{\text {tabel }}(3,339 \leq 4,414)$ atau $\operatorname{sig}_{\text {hit }} \geq \operatorname{sig}_{\text {prob }}(0,84 \geq 0,05)$. Sesuai hipotesis yang diajukan dapat diperoleh simpulan bahwa $\mathrm{H}_{0}$ diterima artinya tidak ada pengaruh harga terhadap volume penjualan mie instan goreng pada minimarket Indomaret Manisrejo di kota Madiun.

\section{Simpulan Uji t}

Dari hasil pengujian yang dilakukan diperoleh persamaan regresi sebagai berikut. $\mathrm{Y}=7709,415-1,789 \mathrm{X}$ maka simpulanya adalah jika harga meningkat 1\% maka volume penjualan akan mengalami penurunan -1,789\% sedangkan faktor lainnya tetap. Hasil dari uji $\mathrm{t}$ diperoleh nilai $\mathrm{t}_{\mathrm{hit}}$ sebesar -1,827 sedangkan $\mathrm{t}_{\text {tabel }}$ sebesar 0,842. Hal ini berarti $\mathrm{t}_{\text {hit }} \leq \mathrm{t}_{\text {tabel }}(-$ $1,827 \leq 0,842)$ atau nilai $\operatorname{sig}_{\text {hit }} \geq \operatorname{sig}_{\text {prob }}\left(0,84 \mathrm{e}^{\text {" }}\right.$ $0,05)$. Maka sesuai hipotesis yang diajukan dapat diperoleh simpulan bahwa $\mathrm{H}_{0}$ diterima, artinya tidak ada beda pengaruh harga terhadap volume penjualan mie instan goreng pada minimarket Indomaret Manisrejo di kota Madiun.

\section{PENUTUP}

\section{Simpulan}

Setelah peneliti melakukan analisa data yang terkait dengan penelitian, maka peneliti dapat menarik kesimpulan sebagai berikut:

Berdasarkan tabel 4.1 pada BAB IV, dapat disimpulkan bahwa harga produk mie instan goreng pada Minimarket Indomaret Manisrejo di Kota Madiun sangat bervariasi dan produk yang pertama kali muncul di pasaran harganya cenderung lebih mahal dibandingkan dengan produk mie instan goreng yang baru muncul di pasaran.

Berdasarkan tabel 4.2 pada BAB IV, dapat disimpulkan bahwa volume penjualan produk mie instan goreng pada Minimarket Indomaret Manisrejo di Kota Madiun yang harganya mahal ternyata lebih banyak dari pada produk mie instan goreng yang harganya lebih murah. Karena biasanya konsumen lebih mengutamakan merek dan rasa yang sesuai dengan selera dalam membeli produk mie instan goreng. Biasanya konsumen sering beranggapan bahwa produk mie instan goreng yang pertama kali muncul dipasaran tersebut 
sudah terlanjur cocok dengan selerannya sehingga konsumen enggan untuk berpindah ke produk lain yang baru muncul di pasaran walaupun harganya lebih murah.

Berdasarkan hasil analisa data yang terdapat pada BAB IV, maka dapat disimpulkan bahwa harga tidak berpengaruh terhadap volume penjualan mie instan goreng pada minimarket Indomaret Manisrejo di kota Madiun. Yang artinya harga mie instan goreng yang murah belum tentu diminati oleh konsumen sehingga mengakibatkan volume penjualan tinggi, dan sebaliknya harga mie instan goreng yang lebih mahal belum tentu tidak diminati oleh konsumen sehingga dapat mengakibatkan volume penjualan menurun. Hal tersebut diatas dipertegas oleh pendapat Kotler, 2009: 78 yang menyatakan bahwa "Kadang-kadang konsumen menerima harga mahal untuk mengindikasikan produk yang lebih baik".

Pendapat Basu Swastha (2002: 149) yang menyatakan bahwa "Orang sering memilih harga yang lebih tinggi di antara dua barang karena mereka melihat adanya perbedaan. Apabila harga lebih tinggi, orang cenderung beranggapan bahwa kualitasnya juga lebih baik".

Serta dipertegas lagi oleh pendapat Kotler (2009: 74) yang menyatakan bahwa "Banyak konsumen menggunakan harga sebagai indikator kualitas".

Jadi konsumen beranggapan bahwa bila harga barang tersebut mahal maka barang tersebut dianggap berkualitas atau lebih sering disebut ber-merek, dan sebaliknya apabila harga barang tersebut murah maka biasanya konsumen beranggapan bahwa barang tersebut kurang berkualitas. Sehingga dalam membeli mie instan biasanya konsumen lebih memperhatikan kualitas dalam hal memilih merek dan rasa mie instan yang bervariasi, dan harga mie instan yang lebih murah belum tentu cocok dengan selera maupun loyalitas konsumen tersebut.

Hasil penelitian ini menunjukan bahwa harga tidak mempunyai pengaruh terhadap volume penjualan mie instan goreng pada minimarket Indomaret Manisrejo di kota Madiun. Yang artinya harga mie instan goreng yang lebih mahal belum tentu tidak diminati oleh konsumen sehingga dapat mengakibatkan volume penjualan menurun. Hal ini disebabkan karena biasanya konsumen lebih memperhatikan faktor merek, rasa, maupun selera dalam membeli produk mie instan.

Pembahasan untuk penelitian ini menggunakan uji regresi (uji korelasi, uji F, dan uji t) adalah sebagai berikut.

\section{PEMBAHASAN UJI KORELASI}

Dalam uji korelasi diperoleh nilai $\mathrm{r}_{\text {hit }} \leq$ $r_{\text {tabel }}(0,396 \leq 0,444)$ atau $\operatorname{sig}_{\text {hit }} \geq \operatorname{sig}_{\text {prob }}(0,84 \geq$ $0,05)$. Diketahui juga bahwa nilai $\mathrm{R}^{2}$ sebesar $15,60 \%$, hal ini menunjukan bahwa hanya sebesar 15,60\% volume penjualan yang dipengaruhi oleh harga, sedangkan sisanya sebesar 84,40\% merupakan faktor lain yang tidak diteliti, misalnya saja faktor selera konsumen, merek, rasa maupun loyalitas konsumen yang dapat berpengaruh terhadap volume penjualan.

Jadi dapat disimpulkan bahwa $\mathrm{H}_{0}$ diterima artinya tidak ada hubungan antara harga terhadap volume penjualan mie instan goreng pada minimarket Indomaret Manisrejo di kota Madiun.

\section{Pembahasan Uji Fisher}

Dalam uji Fisher diperoleh nilai $\mathrm{F}_{\text {hit }} \leq \mathrm{F}_{\text {tabel }}$ $(3,339 \leq 4,414)$ atau $\operatorname{sig}_{\text {hit }} \geq \operatorname{sig}_{\text {prob }}(0,84 \geq 0,05)$. Jadi dapat disimpulkan bahwa $\mathrm{H}_{0}$ diterima artinya tidak ada pengaruh harga terhadap volume penjualan mie instan goreng pada minimarket Indomaret Manisrejo di kota Madiun.

\section{Pembahasan Uji t}

Dapat dilihat dari hasil persamaan regresi diperoleh persamaan $\mathrm{Y}=7709,414$ - 0,840 X sedangkan dalam uji koefisien regresi / uji t diperoleh nilai $\mathrm{t}_{\text {hit }} \leq \mathrm{t}_{\text {tabel }}(-1,827 \leq 0,842)$ atau nilai $\operatorname{sig}_{\text {hit }} \geq \operatorname{sig}_{\text {prob }}(0,84 \geq 0,05)$, maka dapat disimpulkan bahwa $\mathrm{H}_{0}$ diterima, artinya tidak 
ada beda pengaruh harga terhadap volume penjualan mie instan goreng pada minimarket Indomaret Manisrejo di kota Madiun.

\section{DAFTAR PUSTAKA}

Andi Supangat. 2007. Statistika. Jakarta: Kencana Predana Media Group.

Ari Sudarman. 2008. Teori Ekonomi Mikro. Yogyakarta: BPFE.

Basu Swastha. 2002. Azas-Azas Marketing. Yogyakarta: Liberty.

Basu Swastha. 2002. Pengantar Bisnis Modern. Yogyakarta: Liberty.

Basu Swastha. 2008. Manajemen Pemasaran Modern. Yogyakarta: Liberty.

Boyd, Walker, Larreche. “Tanpa tahun” Marketing Managemet. Terjemahan oleh Imam Nurmawan. 2000. Jakarta: Erlangga.

Buchari Alma. 2005. Kewirausahaan. Bandung: Alfabeta.

Burhan Bungin. 2009. Metodologi penelitian Kuantitatif. Jakarta: Kencana Predana Media Group.

Freddy Rangkuti. 2009. Strategi Promosi Yang Efektif. Bogor: PT.Gramedia Pustaka Utama.

Gabriel Amin Silalahi. 2003. Metodologi Penelitian dan Studi Kasus. Sidoarjo: CV Citra Media.

Hendri Ma'ruf. 2006. Pemasaran Ritel. Jakarta: PT Gramedia Pustaka Utama.

Hendry Faizal Noor. 2008. Ekonomi Manajerial. Jakarta: PT Raja Grafindo Persada.

Husein Umar. 2011. Metode Penelitian Untuk Skripsi Dan Tesis Bisnis. Jakarta: PT Raja Grafindo Persada.

Iqbal Hasan. 2004. Analisis Data Penelitian De- ngan Statistik. Jakarta: PT Bumi Aksara.

J. Supranto. 2004. Analisis Multivariat. Jakarta: PT Rineka Cipta.

J. Supranto. 2008. Statistik Teori dan Aplikasi. Jakarta: Erlangga.

Juliansyah Noor. 2011. Metodologi Penelitian. Jakarta: Kencana Predana Media Group.

Kotler, Philip. “Tanpa Tahun”. Marketing in the Public Sector, Terjemahan oleh Taufik Amir. 2007. PT Macanan Jaya Cemerlang.

Kotler, Philip. “Tanpa Tahun”. Marketing Management, Thirteenh Edition, Jilid 2, Terjemahan oleh Bob Sabran. 2009. Erlangga.

Lamb, Hair, McDaniel. “Tanpa Tahun” Marketing. Terjemahan oleh David Octarevia. 2001. Jakarta: Salemba Empat.

M. Suparmoko. 2001. Teori Ekonomi Mikro. Yogyakarta: BPFE.

Munawir. 2010. Analisa Laporan Keuangan. Yogyakarta: Liberty.

Suharsimi Arikunto. 2002. Prosedur Penelitian. Jakarta: PT Rineka Cipta.

Suharsimi Arikunto. 2005. Manajemen Penelitian. Jakarta: PT Rineka Cipta.

Sumadi Suryabrata. 2012. Metodolagi Penelitian. Jakarta: PT Raja Grafindo Persada.

Thamrin Abdullah. 2012. Manajemen Pemasaran. Jakarta: PT Raja Grafindo Persada.

Ujang Sumarwan. 2002. Perilaku Konsumen. Bogor: Ghalia Indonesia

Usman Rianse. 2012. Metodologi Penelitian Sosial dan Ekonomi. Bandung: Alfabeta. 